\title{
EVALUATION OF FLEXURAL AND COMPRESSIVE STRENGTH FOR A BIOACTIVE RESTORATIVE MATERIAL, NANOCOMPOSITE AND RESIN MODIFIED GLASS IONOMER: A COMPARATIVE STUDY
}

\author{
Tayseer Maaly* and Salwa El Sayed**
}

\begin{abstract}
Objectives: To perform a comparison between ACTIVA BioACTIVE restorative, Nano-filled dental composite and RMGIC for compressive and flexural strength. Materials and methods: A total of 60 specimens were made of (ACTIVA Bioactive-, Filtek Z350XT and Ketac Nano-100 RMGI), thirty specimens were prepared for compressive strength testing and the other 30 specimens were prepared for flexural strength testing using two split Teflon molds with different dimensions. All specimens were kept in distilled water for $24 \mathrm{~h}$, then they were tested by universal testing machine. Results: The Filtek Z350XT recorded the highest values for compressive and flexural strength, while the lowest values were for Ketac Nano-100. There was no statistically significant difference between compressive strength values of Filtek Z350XT and ACTIVA. While there were significant difference among flexural strength values for all the materials. Conclusion: ACTIVA demonstrates mechanical properties comparable to dental composite and superior to traditional RMGIC.
\end{abstract}

KEY WORDS: ACTIVA, Flexural strength, RMGIC, Compressive strength, Nano-filled composite.

\section{INTRODUCTION}

The modern restorative dentistry has been extensively influenced by the fast progress in dental restoration technology. The dental clinician has wide variety of direct aesthetic restorative materials including resin composite, glass ionomer, resin modified glass ionomer and recently bioactive restorative.
Wilson and Kent in 1970's introduced a new biomaterial, glass ionomer cements (GICs). This material provided a lot of advantages such as its ability to bond chemically to tooth, biologically compatible, and its anticariogenic properties due to fluoride release ${ }^{1}$. A new modification of conventional GICs was introduced in 1992, the resin modified glass ionomer (RMGI). RMGI has superior mechanical and physical properties in a

* Lecturer of Dental Biomaterials, Faculty of Dentistry, Zagazig University.

** Lecturer of Operative Dentistry, Faculty of Dentistry, Zagazig University. 
comparison with conventional GICs. The early strength of RMGIs were enhanced, they have prolonged working time, enhanced mimic tooth appearance and translucency. ${ }^{2,3}$

RMGICs set by two mechanisms as it contains acid-based and polymerizable components. It bonds to tooth structure by two strategies, micromechanical and chemical bond. The micromechanical interlock achieved by pre-treatment of the tooth using polyacrylic acid exposing collagen network, which is infiltrated by the material. The chemical bond achieved by chelation of the in-organic hydroxyapatite crystals through calcium ions by carboxyl group of the polyacrylic acid. ${ }^{4}$ Enhanced RMGIs were presented to the market in 2013 by Pulpdent Corporation named ACTIVA BioACTIVE restorative material (ACTIVA). Bioactiva is a bioactive composite with ionic resin matrix aiming to enhance both resilience and physical properties ${ }^{5,6}$.

Restorations, in the oral environment, are subjected to mastication force producing stresses. Durability of the restoration depends on its reaction to these different stresses ${ }^{7,8,9}$. Although the clinical performance of dental restoration isn't necessarily correlates with their mechanical properties, understanding the mechanical properties may help to guide the relation between the properties of the materials and the changes in their composition or processing. The clinician may use these data to select between former restorative materials and new ones ${ }^{10}$.

Most of mastication stresses, that the restoration is subjected to, are compressive stresses, so investigation of the restoration under this type of stress is mandatory ${ }^{8}$. In the clinical situation, the restoration is also subjected to flexural stresses ${ }^{4}$. Dental material must be able to withstand the frequent flexing, twisting and bending. The ideal dental material should have high flexural and compressive strength to withstand permanent deformations ${ }^{10}$. The aim of this study was to compare the compressive and flexural strength of composite, traditional RMGIC and enhanced RMGIC namely ACTIVA. The null hypothesis is that: there are no significant differences in compressive and flexural strength between the tested materials.

\section{MATERIALS AND METHODS}

\section{Specimens preparation}

Materials used in the study are shown in table (1). Each specimen was prepared for evaluation of both compressive and flexural strength values following the ISO 9917-2:2010 standard.

TABLE (1): Materials evaluated in the study.

\begin{tabular}{|c|c|c|}
\hline Material & Chemical composition & Manufacturer \\
\hline $\begin{array}{l}\text { ACTIVA } \\
\text { Bioactive- } \\
\text { Restorative }\end{array}$ & $\begin{array}{l}\text { Blend of diurethane and } \\
\text { other methacrylates with } \\
\text { modified polyacrylic acid } \\
\text { Amorphous silica, } \\
\text { Sodium fluoride }\end{array}$ & $\begin{array}{l}\text { Pulpdent } \\
\text { Corporation, } \\
\text { Watertown, } \\
\text { MA USA }\end{array}$ \\
\hline $\begin{array}{l}\text { Filtek } \\
\text { Z350XT }\end{array}$ & $\begin{array}{l}\text { Bis GMA. TEGDM, } \\
\text { UDMA, Bis EMA, } \\
\text { Combination of } \\
\text { aggregated zirconia/ } \\
\text { silica cluster with primary } \\
\text { particle size }(5-20 \mathrm{~nm}), \\
\text { and nonagglomerated } \\
\text { silica filler }(20 \mathrm{~nm}) .\end{array}$ & $\begin{array}{l}\text { 3M ESPE, } \\
\text { St. Paul, } \\
\text { Minnesota, } \\
\text { USA }\end{array}$ \\
\hline $\begin{array}{l}\text { Ketac } \\
\text { Nano-100 } \\
\text { (nano-filled } \\
\text { RMGI) }\end{array}$ & $\begin{array}{l}\text { Silane treated glass, } \\
\text { silane treated Zirconia } \\
\text { Methacrylate-modified } \\
\text { polyalkenoic acid } \\
\text { containing HEMA }\end{array}$ & $\begin{array}{l}\text { 3M ESPE, } \\
\text { Dental } \\
\text { Products, } \\
\text { Seefeld, } \\
\text { Germany }\end{array}$ \\
\hline
\end{tabular}

Bis-GMA: Bisphenol-glycidyl methacrylate; TEGDM: Tri-ethylene glycol dimethacrylate; Bis-EMA: Bis-phenol polyethylene glycol dimethacrylate; UDMA; Urethane ethyl dimethacrylate; HEMA: Hydroxy-ethyl methacrylate

\section{Compressive Strength Test}

A split Teflon mold $(8 \mathrm{~mm}$ height, $4 \mathrm{~mm}$ diameter) was used to prepare cylindrical shaped specimens.The test materials were prepared and 
packed into the mold according to manufacturer's instructions. Two transparent strips of glass plates compressed the material, and then both sides of the sample were polymerized using light-curing device for 40 seconds. Silicon carbide abrasive was used to finish the surfaces of specimens and they were measured by a calliper. Specimens were kept in distilled water at $37^{\circ} \mathrm{C}$ for 24 hours. A testing machine (Zwick DmbH\&Co.KG, Ulm, Germany) was used, at a crosshead speed of $0.5 \mathrm{~mm} / \mathrm{min}$, to evaluate the compressive strength values for specimens. Compressive strength $=\mathrm{P} / \mathrm{A}$, calculated in Mega Pascal, where $\mathrm{P}$ is the load of failure is estimated by newton and $\mathrm{A}$ is the cross-sectional area estimated in $\mathrm{mm}^{2}$.

\section{Flexural Strength Testing}

A total number of thirty specimens with $(2 \times 2$ x $25 \mathrm{~mm}$ ) measurements were fabricated Threepoint bending test was conducted with a cross head speed $0.50 \mathrm{~mm} / \mathrm{min}$ using a universal testing machine (Zwick DmbH \& Co.KG, Ulm, Germany). The length of the distance between the two supports was $20 \mathrm{~mm}$ distance, recording the maximum load which causes failure of specimen. Flexural strength is estimated through the equation $(\alpha)=(3 \mathrm{FL} / 2 \mathrm{bh} 2)$, where F: load at fracture $(\mathrm{N}), \mathrm{L}$ : the specimen length $(\mathrm{mm}), \mathrm{b}$ : the specimen width $(\mathrm{mm})$, and $\mathrm{h}$ : the specimen height $(\mathrm{mm})$.

\section{Statistical Analysis}

Collected values were statistically studied by the software: Version 18, SPSS Inc., Chicago, USA. ANOVA, One way Analysis of variance, and Tukey post hoc test were performed to determine differences between the groups. $P$-value, less than 0.05 , indicated that there is the statistically significant difference.

\section{RESULTS}

Means and standard deviations values of both flexural and compressive strength, for the various groups are shown in Table (2). ANOVA indicated statistically significant difference $(p<0.05)$ of compressive strength values among the various groups. Filtek Z350 XT recorded the highest compressive test values (177.36 \pm 9.1$)$, followed by ACTIVA (164.82 \pm 12.9$)$, without significant difference. Ketac nano-100 had the lowest compressive strength $(153.05 \pm 8.21)$ that is statistically different from that of the other two restorative materials. For flexural test values, ANOVA indicated statistically significant difference between the three tested materials, $(\mathrm{p}<0.05)$. The flexural strength of Filtek Z350XT (99.66 77.74) was the statistically highest one. The flexural strength of ACTIVA (93.15 \pm 6.72$)$ was statistically lower than that of Filtec Z350 ( $<<0.05)$, but statistically higher than ketac nano which record the statistically lowest flexure strength (55.24 \pm 4.98$)$.

TABLE (2) Mean \pm standard deviation of flexural and compressive strength for each group.

\begin{tabular}{|c|c|c|}
\hline Material & $\begin{array}{c}\text { Compressive } \\
\text { strength }(\mathbf{M P a} \pm \text { SD) }\end{array}$ & $\begin{array}{c}\text { Flexural strength } \\
(\mathbf{M P a} \pm \text { SD) }\end{array}$ \\
\hline Filtek Z350 & $177.36 \pm 9.1^{\mathrm{a}}$ & $99.66 \pm 7.74^{\mathrm{a}}$ \\
\hline Bioactiva & $164.82 \pm 12.9^{\mathrm{a}}$ & $93.15 \pm 6.72^{\mathrm{b}}$ \\
\hline Ketac Nano & $153.05 \pm 8.2^{\mathrm{l}} \mathrm{b}$ & $55.24 \pm 4.98^{\mathrm{c}}$ \\
\hline
\end{tabular}

Groups identified with the same superscripted letters are not significantly different $(p<0.05)$.

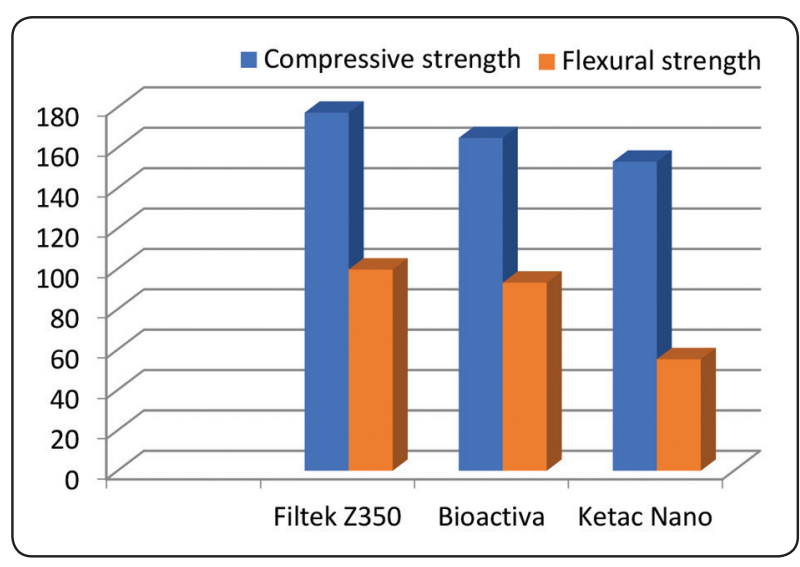

Fig. (1) Comparison of test materials for compressive and flexural strength. 


\section{DISCUSSION}

A full studying of the physical and mechanical properties of biomaterials is very important in dentistry. Most restorative materials must possess adequate mechanical properties to withstand forces in service either during mastication or fabrication. When selecting the restorative materials for clinical use, compressive \& flexural strength are important properties to be considered because tooth and restorations are always subjected to both flexural and compressive forces during the chewing procedure ${ }^{11}$.

In this study, Filtek Z350XT is superior to other two materials in terms of flexural and compressive strength. The results were statistically significant for Ketac Nano-100 regarding both compressive and flexural strength but not statistically significant for compressive strength for ACTIVA. This can be explained by the difference in composition such as type of the monomer and filler content in each material. Filtek Z350XT is a mixture of nanomer sized particle and a nanocluster formulation, this nano-filled structure increased the filler loading and reduces the interstitial spacing resulting in better physical properties when compared to other materials. Filtek Z350XT contains round shaped nanoclusters of Silica and zirconium which have higher contact surface with organic phase, and this may be one reason for the superior behaviour of Filtek Z350XT ${ }^{12,13}$.

Our study evaluated the mean compressive strength for each material to expect their clinical durability and long-lasting in the oral cavity. Compressive strength values for Filtek Z350XT, ACTIVA and Ketac-Nano were higher than (130 $\mathrm{MPa})$, the value of ISO standard ${ }^{14}$. The flexural strength of the materials under transverse bending has been suggested as a way of measuring their brittleness. Flexural strength values for Filtek Z350XT, ACTIVA, were higher than the typical value of ISO (80 MPa), which is acceptable for outer occlusal surface restorations as per ISO standard ${ }^{14}$.

Mechanical properties are affected by monomer composition of the polymer based restorative materials ${ }^{15}$. Bis-GMA (Bisphenol-A glycidylmethacrylate) is composed of an epoxy resin and methyl methacrylate and used as a matrix resin. This composition increases the viscosity and rigidity of the resin ${ }^{16}$. Urethane-dimethacrylate (UDMA) has high flexibility higher molecular weight and low viscosity, resulting in higher flexural strength. BisEMA (ethoxylated version of Bis-GMA) has low viscosity and a high molecular weight exhibits better mechanical properties. Studies reported that flexural strength increases when Bis GMA or TEGDMA are substituted by UDMA ${ }^{17}$. Referring to Table 1, monomers of ACTIVA area mixture of UDMA with other methacrylates. While the monomer component of Filtek Z350 is a mixture of UDMA, Bis-GMA and Bis- EMA and (HEMA) which is hydroxyethyl methacrylate is the monomer of RMGICs.

ACTIVA is different from RMGIS regarding its composition. It is bioactive material consisting of reactive ionomer glass in addition to a shockabsorbing resin component ${ }^{6}$. Compared to RMGIs, ACTIVA exhibits better mechanical and physical properties as reported in previous study ${ }^{6}$. This is explained by the fact of high resilience of ACTIVA against impact forces, as evidenced by the deflection at break values reported in the previous study. In this study, ACTIVA recorded higher compressive and flexural strength values than Ketac Nano 100 RMGIs. These values are accepted for occlusal restorations as they are higher than that specified by ISO standards. This finding is agreeing with previous studies ${ }^{6,18}$, which found that ACTIVA was significantly superior than different commercial types of RMGI regarding the mechanical properties.

\section{CONCLUSIONS}

1. ACTIVA showed comparable properties (Flexure Strength \& Compressive Strength) to Nano-filled resin composite.

2. ACTIVA showed superior mechanical properties to RMGIC.

3. Further laboratory and clinical studies are required to determine the durability of ACTIVA as a restorative material. 


\section{REFERENCES}

1. Saygili G, Mahmali SM. Comparative study of the physical properties of core materials. Int J Periodontic Restorative Dent 2002; 22: 355-63.

2. Qvist V, Poulsen A, Teglers PT, Mjor IA. The longevity of different restorations in primary teeth. Int J Paediatr Dent 2010;20:1-7.

3. Forss H, Widstrom E. Reasons for restorative therapy and the longevity of restorations in adults. Acta Odontol Scand 2004;62:82-6.

4. Anusavice KJ, Shen C, Rawls HR. Phillips' science of dental materials. $12^{\text {th }}$ ed.p 48-69. Elsevier Health Sciences; 2013.

5. Croll TP, Berg JH, Donly KJ. Dental repair material: a resin-modified glass-ionomer bioactive ionic resin-based composite. Compend Contin Educ Dent 2015;36:60-5.

6. Pameijer CH, Garcia-Godoy F, Morrow BR, Jefferies SR. Flexural strength and flexural fatigue properties of resinmodified glass ionomers. J Clin Dent 2015;26:23-7.

7- Albers HF. Tooth-colored restoratives. $8^{\text {th }}$.ed. p 1-17. Santa Rosa: Alto Books; 1996.

8- Craig RG. Restorative dental materials. $10^{\text {th }}$.ed. p. 56-103 St. Louis: Mosby, c1997.

9- Craig RG. Restorative dental materials. $10^{\text {th }}$ ed. p.30-55. St. Louis: Mosby,c1997.

10. Wang L, D'Alpino PH, Lopes LG, Pereira JC. Mechanical properties of dental restorative materials: relative contribution of laboratory tests. J Appl Oral Sci 2003 Sep;11:162-7.

11. Li Y, Lin H, Zheng G, Zhang X, Xu Y. A comparison study on the flexural strength and compressive strength of four resin-modified luting glass ionomer cements. Biomed Mater Eng 2015;26: S9-S17.

12. Moraes R, Gonçalves LdS, Lancellotti A, Consani S, Correr-Sobrinho L, Sinhoreti M. Nanohybrid resin composites: nanofiller loaded materials or traditional microhybrid resins? Oper Dent 2009;34:551-7.

13. George R. Nanocomposites-A review. J Dent Oral Biosciences:20011;2:38-40,

14. International Standard ISO 4049 (2009) Dentistry - Polymer-based restorative materials. International Standards Organization. Fourth edition 2009-10-01

15. Asmussen E, Peutzfeldt A. Influence of UEDMA, BisGMA and TEGDMA on selected mechanical properties of experimental resin composites. Dent Mater 1998;14:51-6.

16. Floyd CJ, Dickens SH. Network structure of Bis-GMA-and UDMA-based resin systems. Dent Mater 2006; 22: 1143-9.

17. Ogliari FA, Ely C, Zanchi CH, Fortes CB, Samuel SM,Demarco FF, Petzhold CL, Piva E. Influence of chain extender length of aromatic dimethacrylates on polymer network development. Dent Mater 2008;24:165-71.

18. Croll TP, Berg JH, Donly KJ. Dental repair material: a resinmodified glass-ionomer bioactive ionic resin-based composite. Compend Contin Educ Dent 2015;36:60-5. 